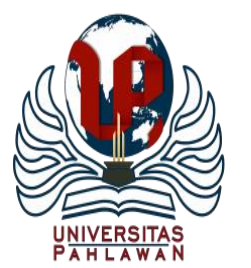

Jurnal Abdidas Volume 2 Nomor 5 Tahun 2021 Halaman 1072-1079

JURNAL ABDIDAS

http://abdidas.org/index.php/abdidas

\title{
Pelatihan Bahasa Inggris Interaktif di Masa Pandemi Covid-19 kepada Freelance Driver di Sanur Bali
}

\author{
Dewa Ayu Kadek Claria ${ }^{1 凶}$, I Gusti Ngurah Adi Rajistha ${ }^{2}$ \\ Sastra Inggris, Universitas Warmadewa, Indonesia ${ }^{1,2}$ \\ E-mail : clariadewaayu@gmail.com ${ }^{1}$ ngurah.adi.rajistha@gmail.com ${ }^{2}$
}

\begin{abstract}
Abstrak
Freelance Driver di Sanur Bali mengalami lonjakan jumlah anggota pada masa pandemi Covid-19 yang merupakan dampak dari adanya pemutusan hubungan kerja para anggota yang sebelumnya bekerja di berbagai sektor wisata di Bali seperti hotel dan restoran. Freelance Driver yang bergerak di bidang pelayanan dan jasa yang berada di sektor pariwisata ini perlu mendapat pendampingan berupa pelatihan bahasa Inggris interaktif sehingga dengan meningkatnya kemampuan berbahasa Inggris yang dimiliki oleh Driver Freelance dapat dijadikan bekal dalam menjalankan profesi baru mereka. Pelatihan bahasa Inggris dalam bentuk interaktif ini memanfaatkan media Zoom Meeting sebagai media utama. Bentuk pelatihan yang diberikan dibagi menjadi tiga tahapan yaitu; (1) tahap ice breaking, (2) tahap pemberian materi dan (3) tahap evaluasi. Seluruh tahap tersebut menerapkan metode komunikasi dua arah sehingga dapat membangun rasa percaya diri peserta pelatihan dalam berinteraksi menggunakan bahasa Inggris dengan lawan bicara. Pada tahap evaluasi diperoleh hasil meningkatnya kemampuan dasar berbahasa Inggris Freelance Driver. Peningkatan kemampuan para Freelance Driver dapat dilihat melalui perbandingan hasil pengisian kuesioner yang dilakukan pada tahap penjajagan dan pada saat akhir pelatihan sebagai perbandingan hasil evaluasi.
\end{abstract}

Kata kunci: freelance driver, Covid-19, bahasa Inggris interaktif

\begin{abstract}
The member of Freelance Driver in Sanur Bali has been increased during the Covid-19 pandemic which was the impact of the termination of employment who previously worked in various tourism sectors in Bali such as hotels and restaurants. Freelance driver who are related with services and hospitality which is in tourism sector need an assistance in the form of interactive English training so that by the increasing of the Freelance Driver's English language skills, they can used it for their new job. This interactive English training uses zoom meeting as the main medium. The form of the training is divided into three stages, namely; (1) the ice breaking step, (2) giving the material and (3) the evaluation step. All of these step apply a two-way communication method to build the trainees' confidence in speaking English. In evaluation step, the results shows that the English proficiency of the Freelance Driver is increasing and it can be seen from the questionnaire filled by the Drivers at the beggining for the assessment step and the end of the training as a comparison for the evaluation results.
\end{abstract}

Keywords: freelance driver; Covid-19; english interactive,

Copyright (c) 2021 Dewa Ayu Kadek Claria, I Gusti Ngurah Adi Rajistha

$\triangle$ Corresponding author

Address : Jl. Terompong No. 24 Denpasar Bali

Email : clariadewaayu@gmail.com

ISSN 2721-9224 (Media Cetak)

DOI $\quad:$ https://doi.org/10.31004/abdidas.v2i5.432

ISSN 2721- 9216 (Media Online)

Jurnal Abdidas Vol 2 No 5 Tahun 2021 p-ISSN 2721-9224 e-ISSN 2721-9216 
1073 Pelatihan Bahasa Inggris Interaktif di Masa Pandemi Covid-19 kepada Freelance Driver di Sanur Bali - Dewa Ayu Kadek Claria, I Gusti Ngurah Adi Rajistha

DOI: https://doi.org/10.31004/abdidas.v2i5.432

\section{PENDAHULUAN}

Pada masa pandemi Covid-19 ini, pelatihan menggunakan media daring adalah hal yang paling memungkinkan untuk dilaksanakan. Adanya jeda dalam dunia pariwisata ini dapat dijadikan kesempatan oleh para pelaku pariwisata untuk mengembangkan kemampuan berbahasa Inggris yang telah dimiliki sebelumnya dengan mengikuti pelatihan secara daring guna meningkatkan kemampuan berbahasa Inggris dalam bidang pelayanan. Hal ini dilakukan juga oleh para Freelance Driver di Sanur Bali selama masa pandemi Covid-19.

Freelance Driver yang saat ini mempunyai banyak waktu luang akibat menurunnya jumlah wisatawan memiliki kesempatan untuk mengembangkan kemampuan mereka dalam menggunakan bahasa Inggris di bidang pelayanan. Disamping itu, jumlah Freelance Driver di Sanur Bali mengalami lonjakan pada masa pandemi Covid-19 yang merupakan dampak dari adanya pemutusan hubungan kerja para anggota yang sebelumnya bekerja di berbagai sektor wisata di Bali baik di hotel maupun restoran.

Bertambahnya jumlah anggota freelance driver di Sanur yang mana profesi tersebut bergerak di bidang jasa dan juga berada di lingkungan pariwisata ini perlu mendapat pendampingan berupa pelatihan bahasa Inggris interaktif. Dengan diadakannya pelatihan bahasa Inggris bagi para freelance driver diharapkan dapat meningkatnya kemampuan berbahasa Inggris para freelance driver sekaligus dapat dijadikan bekal dalam menjalankan profesi baru mereka. Para pengemudi yang berkecimpung dalam dunia pariwisata sebagai pelaku wisata apabila tergabung dalam bisnis berskala besar seperti travel agent, pengemudi taksi yang berada di bawah naungan perusahaan maupun guide yang bekerjasama dengan hotel dan restauran pada umumnya telah memiliki jaminan sumber daya manusia yang memadai terutama dalam hal kemampuan berbahasa Inggris (Dewa Ayu Kadek Claria \& Rajistha, 2020).

Berbeda halnya dengan para freelance driver yang saat ini bekerja secara berdikari sehingga perlu mendapat pendampingan berupa pelatihan bahasa Inggris. Pelatihan serupa pernah dilakukan sebelumnya pada bulan Maret-Juni 2020 terhadap para pengemudi taksi di Desa Sanur Bali yang berada di bawah naungan Yayasan Pembangunan Sanur yang bekerjasama dengan hotel-hotel yang berada di wilayah Sanur. Pada saat pelatihan tersebut kemudian diperoleh potensi dan masalah baru yang muncul di masa pandemi Covid-19 yang dialami oleh para freelance driver yang baru menekuni profesi sebagai pengemudi lepasan atau harian sebagai profesi baru selepas kehilangan pekerjaan. Profesi sebagai freelance driver yang ditekuni secara dadakan mengakibatkan kesiapan dalam penggunaan bahasa Inggris dalam berkomunikasi khusus antara pengemudi dan penumpang belum maksimal.

Adanya kesempatan melaksanakan pelatihan di tengah pandemi Covid-19 ini dimanfaatkan untuk menjawab permasalahan tersebut dengan melakukan pelatihan bahasa Inggris interaktif dengan menggunakan metode pelatihan melalui media Zoom Meeting. Pelatihan bahasa Inggris interaktif ini memiliki tujuan untuk membangun 
1074 Pelatihan Bahasa Inggris Interaktif di Masa Pandemi Covid-19 kepada Freelance Driver di Sanur Bali - Dewa Ayu Kadek Claria, I Gusti Ngurah Adi Rajistha

DOI: https://doi.org/10.31004/abdidas.v2i5.432

pembelajaran yang bersifat aktif. Dalam pembelajaran bahasa Inggris interaktif yang dilakukannya terhadap siswa di SMP menemukan bahwa metode pelatihan berbicara interaktif memiliki fokus pada bentuk interaksi yang terjadi pada saat pelatihan sehingga melalui interaksi yang terjadi pada saat pelatihan dapat dipakai di kemudian hari dalam kehidupan sehari-hari (Mufliharsi, Risa \& Candra, 2018). Selain bentuk interaksi tersebut, penggunaan kalimat persuasif juga sangat diperlukan dalam pelaksnaan pelatihan untuk membangun kelas yang aktif dalam komunikasi (Claria, D.A.K \& Sariani, 2020).

Pembelajaran aktif yaitu dalam artian peserta pelatihan dapat memiliki ketertarikan atau minat yang tinggi terhadap materi yang diberikan dalam proses pembelajaran (Fayombo, 2012). Dalam pelatihan bahasa Inggris, materi dasar banyak diberikan sebagai bentuk pemantapan dari penguasaan tenses. Pelatihan dan pembelajaran di masa pandemi memerlukan persiapan yang lebih matang yang mana proses dalam pembelajaran daring memiliki penerapan yang berbeda dengan konsep pembelajaran tatap muka (Suputra, P.E.D, 2020).

Untuk mendata kemampuan dan kebutuhan bahasa Inggris para freelance driver di Sanur Bali, analisis terhadap kemampuan dasar sekaligus minat para freelance driver dilakukan agar nantinya diperoleh solusi dari permasalahan yang dihadapi. Analisis dasar ini dilakukan mengacu pada dua prinsip dasar di dalam menganalisis permasalahan dengan menggunakan pendekatan target need dan learning need (Hutchinson, Tom $\&$ Waters, 1987). Target need merupakan hal mendasar yang kemudian menjadi kebutuhan dari para freelance driver yang merupakan peserta dalam pelatihan ini. Kebutuhan yang diperoleh melalui pendekatan yang telah dilakukan kemudian disesuaikan dengan situasi yang terjadi yaitu dalam hal ini perlunya pelatihan bahasa Inggris interaktif dengan menggunakan media zoom di masa pandemi Covid-19 sehingga apa yang menjadi kebutuhan para freelance driver sesuai dengan keadaan dan kebutuhan di lapangan.

Pada pelatihan bahasa Inggris Interaktif ini, materi yang diberikan diambil dari materi pelatihan bahasa Inggris khusus bagi para pengemudi taksi karena menyesuaikan dengan kebutuhan para freelance driver yang mana materi tersebut dapat digunakan untuk meningkatkan kemampuan berkomunikasi para Freelance Driver secara interaktif. Materi pelatihan bahasa Inggris untuk pengemudi taksi dibuat dan disesuaikan dengan bahasa Inggris untuk kebutuhan khusus atau dikenal dengan sebutan English for specific purposes (Dewa Ayu Kadek Claria, 2020).

Penggunaan kalimat imperatif juga disematkan dalam pelatihan ini karena kalimat imperatif dalam bahasa Inggris juga dapat digunakan untuk berkomunikasi secara dua arah atau interaktif (D.A.K. Claria, 2021). Salah satu faktor yang mempengaruhi jumlah kunjungan wisatawan adalah adanya bentuk pelayanan yang diharapkan dapat memuaskan konsumen sehingga dapat dikatakan bahwa hal tersebut sangatlah berkaitan dengan komunikasi khususnya dalam hal berkomunikasi dengan menggunakan bahasa Inggris (Bhar, S.K., Bakar, N.A, 2012). Mengembangkan kemampuan berbahasa Inggris 
1075 Pelatihan Bahasa Inggris Interaktif di Masa Pandemi Covid-19 kepada Freelance Driver di Sanur Bali - Dewa Ayu Kadek Claria, I Gusti Ngurah Adi Rajistha

DOI: https://doi.org/10.31004/abdidas.v2i5.432

para pengemudi baik itu pengemudi taksi, travel maupun freelance driver merupakan hal yang sangat penting untuk dilakukan.

Pada masa pandemi pelatihan dengan memaksimalkan media daring sangat membantu dalam proses pembelajaran. Metode pembelajaran degan media daring dapat memberikan dampak maupun kontribusi yang sangat besar dalam terciptanya suatu pembelajaran yang efisien dan menarik (Wiyono, 2015). Satu-satunya cara agar pelatihan dapat berjalan di masa pandemi Covid19 ini adalah dengan memanfaatkan salah satu media pembelajaran maupun media daring lainnya yang dapat menunjang proses pembelajaran. Penggunaan media daring tidak dapat dipungkiri memang membawa andil yang besar dalam proses pembelajaran (Riyana, 2010).

Pada masa sebelum pandemi terjadi, pembelajaran dengan menggunakan media daring untuk meningkatkan kualitas pendidikan telah dilakukan sebelumnya sehingga pemanfaatan media dan teknologi di masa pandemi ini merupakan pilihan yang tepat untuk tetap memperoleh hasil yang maksimal dari proses pelatihan dan pembelajaran. Sasaran dari kegiatan pengabdian ini adalah para freelance driver di Desa Bali. Dalam proses pembelajaran, memanfaatkan media daring sangat berhubungan erat dengan teknologi sehingga harus mengikuti konsep pembelajaran yang berpusat pada siswa dengan desain pembelajaran yang bersifat fleksibel dan dapat menyesuaikan dengan kebutuhan (Carrillo, C., \& Flores, 2020).

\section{METODE}

Kegiatan pelatihan bahasa Inggris interaktif dengan menggunakan media Zoom Meeting ini dapat terlaksana melalui beberapa proses atau tahapan persiapan sehingga dapat menghasilkan pelatihan yang maksimal. Adapun tahapan-tahapan dalam pelaksanaan kegiatan pelatihan ini adalah sebagai berikut.

\section{Pengumpulan Data Potensi dan Masalah}

Data potensi dan masalah didapat melalui proses survei lapangan dan tahapan wawancara kepada mitra. Survei lapangan dilakukan untuk mengetahui potensi masalah yang dihadapi oleh para freelance driver di lapangan selama masa pandemi covid-19. Tahapan survey lapangan juga dikombinasikan dengan dilakukannya wawancara sebagai bentuk pendekatan terhadap para freelance driver untuk memperoleh data yang lebih akurat terkait kebutuhan para pengemudi terkait pelatihan bahasa Inggris yang diberikan. Proses wawancara dipandu dengan list pertanyaan yang telah disiapkan dan diakhiri dengan pengisian kuesioner untuk mengukur kemampuan awal para freelance driver.

\section{Pengolahan Data Potensi dan Masalah}

Data yang diperoleh saat survei kemudian dipilah dan ditelaah untuk memperoleh jenis pelatihan yang sesuai yang kemudian digunakan sebagai konsep utama dalam pelaksanaan pelatihan bahasa Inggris. Dari hasil pengolahan data diperoleh kesimpulan bahwa dari 30 orang freelance driver sebanyak 18 orang menginginkan adanya pelatihan bahasa Inggris interaktif yang 
1076 Pelatihan Bahasa Inggris Interaktif di Masa Pandemi Covid-19 kepada Freelance Driver di Sanur Bali - Dewa Ayu Kadek Claria, I Gusti Ngurah Adi Rajistha

DOI: https://doi.org/10.31004/abdidas.v2i5.432

dapat meningkatkan kemampuan mereka dalam berkomunikasi. Sedangkan 12 orang lainnya mengingkan adanya pelatihan bahasa Inggris khusus di bidang pelayanan.

\section{Pelaksanaan Pelatihan Bahasa Inggris}

Berdasarkan hasil survei dan pengolahan potensi masalah, maka pelatihan bahasa Inggris yang diberikan pada para freelance driver ini ditetapkan menggunakan pelatihan dengan metode interaktif dengan materi yang diambil adalah materi bahasa Inggris yang dapat menunjang profesi di bidang pelayanan sebagai seorang pengemudi yang bekerja di sektor pariwisata. Kegiatan dilaksanakan dengan mengoptimalkan media pelatihan melalui daring yaitu menggunakan media Zoom Meeting.

\section{HASIL DAN PEMBAHASAN}

Pelatihan dilaksanakan pada hari Sabtu, 31 Oktober 2020 pukul 08.00 s.d 16.00 WITA dengan jumlah peserta pelatihan sebanyak 18 orang yang merupakan para freelance driver yang menginginkan pelatihan bahasa Inggris dasar untuk meningkatkan kemampuan berkomunikasi. Pelatihan dilakukan dengan memanfaatkan media Zoom Meeting sehingga pelatihan dapat terlaksana secara tatap muka sebagai modal utama dalam pelatihan bahasa Inggris interaktif.

Pelatihan dilaksanakan melalui tiga tahapan yaitu, (1) tahap ice breaking, (2) tahap pemberian materi dan (3) tahap evaluasi. Pada tahapan pertama, percakapan dua arah secara ringan dilakukan untuk memperoleh suasana yang nyaman pada saat pembelajaran sekaligus membangun komunikasi interaktif dari para freelance driver.

Pada tahapan ice breaking yang diawali dengan informasi umum tentang bahasa Inggris yang kemudian diselipkan dengan pertanyaanpertanyaan yang diajukan kepada para freelance driver terkait penggunaan pemarkah waktu (tenses) dan fungsi-fungsi bahasa (language function) untuk mengetahui lebih jauh kemampuan para freelance driver terhadap bahasa Inggris dasar.

Pemberian materi yang berupa percakapan bahasa Inggris yang umumnya digunakan oleh para pengemudi taksi dalam bidang pelayanan kemudian diterapkan di sela-sela perbincangan dua arah yang dilakukan pada saat pelatihan. Materi juga diberkan dalam bentuk soft copy yang telah dikirimkan melalui fitur chat yang tersedia pada media Zoom Meeting.

Pemberian materi dilakukan juga dengan memberikan simulasi dan contoh percakapan melalui video yang ditayangkan melalui zoom meeting sehingga peserta pelatihan dapat melihat langsung bentuk percakapan yang digunakan oleh para pengemudi taksi saat berinteraksi dengan penumpang. Peserta pelatihan juga diminta untuk terus berinteraksi melalui praktik pada saat pelatihan. Praktik yang dilakukan berupa mengulangi kembali bentuk-bentuk percakapan yang diberikan dan mencoba mencari bentukbentuk percakapan baru yang biasanya dilakukan oleh para pengemudi sebagai bentuk pelayanan dengan menggunakan bahasa Inggris.

Tahapan akhir dari pelatihan merupakan tahap evaluasi. Evaluasi dilakukan untuk menilhat 
1077 Pelatihan Bahasa Inggris Interaktif di Masa Pandemi Covid-19 kepada Freelance Driver di Sanur Bali - Dewa Ayu Kadek Claria, I Gusti Ngurah Adi Rajistha

DOI: https://doi.org/10.31004/abdidas.v2i5.432

sejauh mana keberhasilan para freelance driver dalam memahami materi sekaligus untuk meninjau keberhasilan pelatihan bahasa Inggris interaktif dengan materi bahasa Inggris dasar yang pada umumnya digunakan dalam berkomunikasi oleh para pengemudi taksi.

Evaluasi dilakukan dengan mengirimkan link pertanyaan pada fitur chat yang harus diisi oleh para freelance driver pada saat akhir pelatihan. Link evaluasi diberikan dalam bentuk google form sehingga dapat diperoleh ukuran atau capaian yang akurat dari para freelance driver setelah diadakannya pelatihan. Kegiatan pelatihan bahasa Inggris dengan memanfaatkan media Zoom Meeting ini diabadikan melalui beberapa foto sebagai berikut;
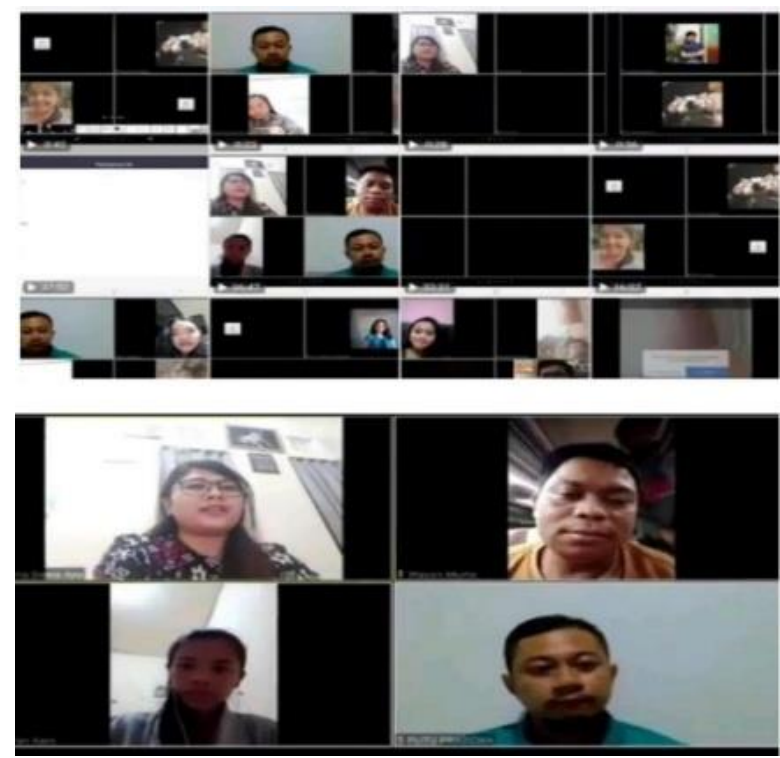

Gambar 1. Pelatihan Bahasa Inggris Interaktif menggunakan media Zoom Meeting

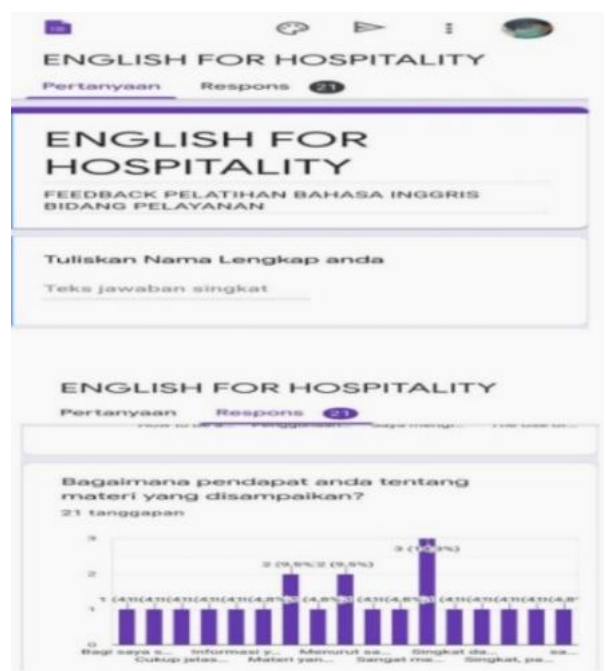

Gambar 2. Evaluasi kemampuan Peserta

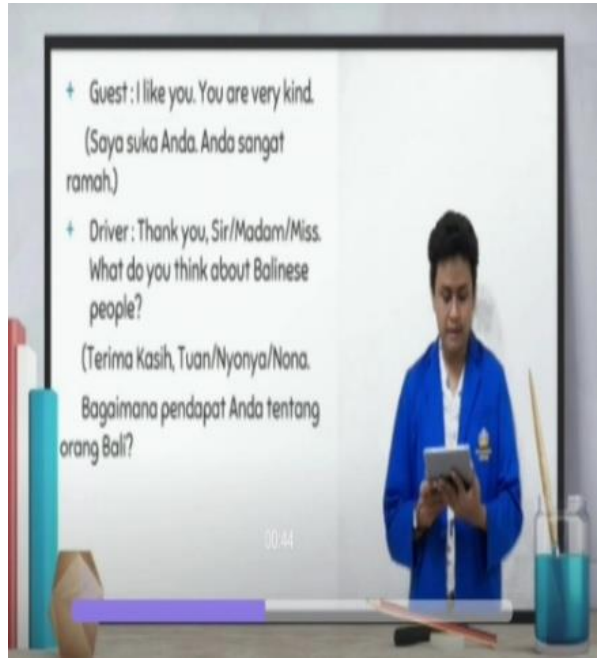

Gambar 3. Video Interaktif Percakapan Bahasa Inggris antara Pengemudi dan Penumpang

Melalui pelatihan bahasa Inggris interaktif yang telah dilaksanakan terhadap para freelance driver melalui media Zoom diperoleh hasil yaitu; (1) peserta pelatihan yang baru berprofesi sebagai freelance driver akibat terdampak pandemi Covid19 dapat memiliki pengetahun baru tentang penggunaan bahasa Inggris yang umumnya digunakan untuk berkomunikasi oleh para pengemudi taksi secara interaktif sekaligus memperoleh manfaat tambahan dalam hal 
1078 Pelatihan Bahasa Inggris Interaktif di Masa Pandemi Covid-19 kepada Freelance Driver di Sanur Bali - Dewa Ayu Kadek Claria, I Gusti Ngurah Adi Rajistha

DOI: https://doi.org/10.31004/abdidas.v2i5.432

penggunaan media Zoom sebagi media interaksi yang dapat digunakan sebagai media pembelajaran. Sebanyak $80 \%$ peserta pelatihan dapat memahami materi dengan baik.

\section{SIMPULAN}

Kegiatan pelatihan bahasa Inggris interaktif dengan memanfaatkan media Zoom ini merupakan bentuk dari pengabdian kepada masyarakat di masa pandemi Covid-19 dengan menyasar para freelance driver yang terdampak pandemi sebagai peserta pelatihan. Dengan diadakannya pelatihan ini, para freelance driver dapat memanfaatkan waktu luang yang dimiliki sekaligus memperoleh wawasan baru di bidang bahasa Inggris yang dapat menunjang profesi mereka yang bergerak di bidang jasa dan berada di lingkungan pariwisata. Meskipun pada saat pandemi, kunjungan pariwisata menurun, namun dampak positif yang diperoleh oleh para pengemudi adalah meningkatnya kemampuan dan wawasan para freelance driver dalam hal berkomunikasi secara interaktif dalam bidang pelayanan yang kemudian dapat terus menunjang profesi mereka di masa yang akan datang. Dari kegiatan tersebut dapat disimpulkan bahwa pelatihan bahasa Inggris dengan media zoom sangat efektif dilakukan di masa pandemi Covid-19 dilihat dari keberhasilan pelatihan yang tercermin dalam hasil evaluasi berupa meningkatkan kemampuan berbahasa Inggris para freelance driver yang dapat digunakan untuk menunjang profesi mereka yang baru sebagai seorang pengemudi atau freelance driver.

Pelatihan bahasa Inggris interaktif yang diberikan kepada para freelance driver mendapatkan hasil yang memuaskan dari dan juga tanggapan yang positif dari para pengemudi berupa antusiasme para freelance driver pada saat pelatihan membawa harapan yang besar agar pelatihan bahasa Inggris yang serupa dapat dilakukan di masa pandemi Covid-19 ini untuk memanfaatkan waktu jeda bagi para pelaku wisata. Hal serupa dapat dilakukan dengan menyasar para pelaku lainnya sehingga meskipun pariwisata pada masa pandemi sedang terpuruk, hal positif lainnya dapat dilakukan seperti meningkatkan kemampuan berbahasa Inggris dari sumber daya manusia yang ada.

\section{UCAPAN TERIMA KASIH}

Ucapan terima kasih disampaikan kepada pihak-pihak yang terlibat dalam kegiatan ini yaitu Lembaga Penelitian dan Pengabdian Masyarakat (LPPM) Universitas Warmadewa yang telah mendukung dan memberikan dana untuk dapat melaksanakan pengabdian masyarakat ini. Ucapan terima kasih juga disampaikan kepada mitra dalam pengabdian masyarakat ini yaitu para freelance driver di Sanur Bali yang berada di bawah pengawasan Yayasan Pembangunan Sanur (YPS) yang telah memberikan izin sehingga pelatihan dapat berjalan dengan baik dan lancar.

\section{DAFTAR PUSTAKA}

Bhar, S.K., Bakar, N.A. (2012). No Language Barriers: Feedback from the IT IndustryTitle. Journal of Technical Education \& Training, 4(2), 9-20.

Carrillo, C., \& Flores, M. A. (2020). COVID-19 and teacher education: a literarture review of online teaching and learning practices. European Journal of Teacher Education, 
1079 Pelatihan Bahasa Inggris Interaktif di Masa Pandemi Covid-19 kepada Freelance Driver di Sanur Bali - Dewa Ayu Kadek Claria, I Gusti Ngurah Adi Rajistha

DOI: https://doi.org/10.31004/abdidas.v2i5.432

43(4), 466-487.

Claria, D.A.K \& Sariani, N. . (2020). Metode Komunikasi Persuasif untuk Meningkatkan Motivasi Berwirausaha Masyarakat di Desa Kesiman Kertalangu pada Masa Pandemi Covid-19.

https://www.ejournal.warmadewa.ac.id/index .php/licosjournal/article/view/2281

Claria, D. A. K. . (2021). Sosialisasi Penggunaan Kalimat Imperatif Sebagai Strategi Pemasaran UMKM pada Masa Pandemi Covid-19 di Desa Pejeng Gianyar. Jurnal Abdidas, 2(3), 472-482. https://doi.org/10.31004/abdidas.v2i3.300.

Claria, Dewa Ayu Kadek. (2020). Creating an English Materials in Oral Discourse Aspect for The Taxi Drivers. KULTURISTIK: Jurnal Bahasa Dan Budaya, 4(1), 16-21. https://doi.org/10.22225/kulturistik.4.1.1556

Claria, Dewa Ayu Kadek, \& Rajistha, I. G. N. A. R. (2020). Optimalisasi Penggunaan Media Daring dalam Pelatihan Bahasa Inggris Bidang Pelayanan Untuk Para Pengemudi Taksi di Desa Sanur Bali. Dedication: Jurnal Pengabdian Masyarakat, 4(2), 81-91. https://doi.org/10.31537/dedication.v4i2.356

Fayombo, G. A. (2012). Active learning strategies and student learning outcomes among some university students in Barbados. Journal of Educational and Social Research, 2(9), 7979.

https://doi.org/10.5901/jesr.2012.v2n9p79

Hutchinson, Tom \& Waters, A. (1987). English for Spesific Purpose. https://www.academia.edu/4831921/English_ for_specific_purposes_hutchinson_tom_wate rs_alan

Mufliharsi, Risa \& Candra, E. . (2018). Pembelajaran Berbicara Interaktif Bahasa Inggris di SMP. JPP IPTEK, 2(2), 35-40. https://doi.org/10.31284/j.jppiptek.2018.v2i2.297

Riyana, C. (2010). Peningkatan Kompetensi Pedagogis Guru Melalui Penerapan Model Education Centre of Teacher Interactive Virtual. Jurnal Penelitian Pendidikan, 11(1),
$40-48$.

Suputra, P.E.D, dkk. (2020). Kelas Daring Bahasa Inggris di Masa Pandemi: Sebuah Tantangan Pembelajaran. Seminar Nasional Riset Inovatif 2020.

Wiyono, K. (2015). Pengembangan Model Pembelajaran Berbasis ICT pada Implemetasi Kurikulum 2013. Jurnal Inovasi Dan Pembelajaran Fisika, 2(2), 123-131. 